\title{
La Comisión Mexicana de Límites y la definición de la frontera sur del país ${ }^{1}$
}

\author{
Luz María Oralia Tamayo Pérez²
}

\begin{abstract}
RESUMEN
La Geografía en México tiene una historia interesante; los especialistas que la practicaron en el pasado hicieron importantes aportaciones al conocimiento del territorio nacional y al avance de la misma disciplina. Un ejemplo fue la definición de las fronteras que, como las de otros países de América Latina, se realizó en los siglos XIX y XX. El trabajo científico de los ingenieros geógrafos de la Comisión Mexicana de Límites permitió colocar sobre el terreno las señales indicadoras de los elementos que separan a esta República de sus vecinos y, con ello, se logró la conformación del espacio nacional. El objetivo de esta investigación es responder a la pregunta: ¿Cómo se hizo la demarcación del límite que divide a México de Guatemala y de Belice?; para lograrlo se analizaron los documentos y la cartografía contenidos en archivos históricos del país; sus resultados aportan elementos para la Historia de la Geografía Mexicana.
\end{abstract}

Palabras clave: Frontera, Comisión de Límites, Cartografía histórica, México.

\begin{abstract}
Geography in Mexico has an interesting but little known history. Geographers in the past made important contributions both to the recognition of the country and to the advancement of this discipline. One example is the definition of Mexico's borders. In Mexico, as in Latin America, the definition of borders occurred in the nineteenth and twentieth centuries. The scientific work developed by the geographic engineers of the Mexican border commission allowed for the placement of landmarks that separate Mexico from its neighboring countries. This allowed the conformation of the National territory. The purpose of this research is to answer the question: How was the border that separates Mexico from Guatemala and Belize demarcated? In order to answer this question, documents and maps contained in Mexican Historical Archives were analyzed. This paper provides elements to the History of the Mexican Geography.
\end{abstract}

Key words: Border, Border Commission, historical cartography, México.

\footnotetext{
1 La autora agradece al Lic. Carlos Vidalí jefe de la Mapoteca Manuel Orozco y Berra de la Secretaría de Agricultura, Ganadería, Desarrollo Rural, Pesca y Alimentación (SAGARPA), y al Sr. Daniel Montiel S., trabajador de la misma Mapoteca, así como al personal del Archivo de la Secretaría de Relaciones Exteriores por su disposición para facilitarme el acceso a los valiosos documentos que resguardan a la Lic. María de Lourdes Godínez Calderón por la
}

elaboración o arreglo de los mapas, a la Lic. María Elena Cea Herrera por la revisión de estilo. Artículo recibido el 3 de julio de 2014, aceptado el 11 de diciembre de 2014 y corregido el 20 de enero de 2015.

2 Instituto de Geografía, Universidad Nacional Autónoma de México (México).

E-mail:ptamayo@unam.mx 
La globalización, en algunos casos, ha diluido las fronteras transformándolas en espacios de intercambio y cooperación, pero en otros, las diferencias socioeconómicas entre los países han propiciado el endurecimiento de las mismas, con el fin de detener la migración procedente de países del tercer mundo. Las fronteras y los límites han variado en importancia a lo largo de la historia, desde una total inexistencia en tiempos muy antiguos, hasta constituir un elemento importante para la definición del espacio correspondiente a una nación.

El territorio nacional es la porción de la superficie terrestre que pertenece a un país; es el espacio que definen sus fronteras, que pertenece al pueblo que lo habita y en donde el Estado ejerce su soberanía. Al determinar sus límites se posibilita el conocimiento del espacio con el fin de que el Estado organice sus instituciones para planear el desarrollo y bienestar social de su pueblo. Si bien los términos límite y frontera generalmente son utilizados como sinónimos, la palabra límite se asocia con una línea que separa a dos territorios sujetos a diferentes soberanías, y comúnmente se traza en mapas; en cambio, la frontera se refiere a una región que, aunque tiene características lineales en el terreno, más que una línea es una zona. A lo largo de la historia se han utilizado como límites naturales algunos accidentes geográficos como ríos permanentes, cadenas montañosas y otras irregularidades del terreno, su importancia como frontera se la dan los acuerdos políticos establecidos entre las naciones involucradas (Martin 1992, En: Muratori, 2007: 15). Las líneas limítrofes en algunos casos confrontan modos de vida totalmente desiguales, provocando migraciones y movimientos poblacionales desde países menos desarrollados hacia otros con mejores oportunidades y condiciones de vida. Por tanto, en el sentido formal, las fronteras constituyen el límite del ejercicio del poder del Estado y le permiten prohibir o autorizar el paso; equivalen a puertas que se abren o se cierran de acuerdo a intereses políticos (Moura y Morin, en: Muratori, 2007: 16).

Las fronteras formales ${ }^{3}$ pueden ser naturales o artificiales, y se señalan en los mapas,

\footnotetext{
3 Las fronteras pueden ser formales, simbólicas, vivas o muertas y blandas o duras (Martin, 1992, En: Muratori, 2007: 16-17)
}

las naturales son visibles 4 en el terreno y las artificiales son invisibles ${ }^{5}$. La frontera es considerada como una zona de transición entre dos espacios diferentes, en medio de la cual se encuentra el límite o línea divisoria entre dos países. Así, la frontera cumple una función dual, por un lado representa una barrera que divide, impide o bloquea el paso de personas, y por otro, es una membrana permeable que filtra el libre paso de personas (Taylor, 1996: 34).

Por diferentes razones, los pueblos siempre han dividido el espacio en el que viven, ya sea, para identificarse como miembros de un grupo social con características similares o para resguardar la seguridad de su grupo y el control de su territorio. A lo largo de la historia existen diversos ejemplos a este respecto ${ }^{6}$, pero fue hasta después de la derrota de $\mathrm{Na}$ poleón cuando, principalmente en Europa, las fronteras y las líneas limítrofes adquirieron un carácter estratégico y una finalidad diplomática; fue obligatorio para las naciones fijar límites precisos; se establecieron aduanas y conceptos como nación, nacionalismo o soberanía, y otros ya identificados por pensadores adquirieron mayor significación ${ }^{7}$. La demarcación de los países en Europa se facilitó relativamente con los descubrimientos científicos y tecnológicos, que permitieron la medición de tierras y la elaboración de cartografía científica (Taylor, 1996: 35-39). América Latina en cambio, debido a sus riquezas naturales fue objeto de la codicia de otras naciones ${ }^{8}$, con el establecimiento de virreinatos y capitanías generales; los conquistadores

\footnotetext{
4 Están definidas por ríos, lagos, mares, cadenas montañosas y otros accidentes geográficos (Muratori 2007: 17)

5 Son líneas imaginarias basadas principalmente en paralelos y meridianos obtenidos por métodos astronómicos o geodésicos (Muratori, 2007: 17)

6 Entre otras están las fortalezas en los castillos medievales y las murallas en las principales ciudades de la antigüedad; la más notable es la Gran Muralla China

7 En 1897, Ratzel escribió su Geografía Política y en esta obra destaca la importancia del espacio geopolítico del Estado ya que, [señala] el Estado no se concibe sin territorio (Higueras, 2007: 45)

8 Por ejemplo, los imperios Azteca, Maya e Inca dominaban extensos territorios, pero, al ser conquistados, fueron arrasados para extraer de ellos los ricos minerales que contenían sus posesiones (Muratori, 2007: 127).
} 
Figura $\mathrm{N}^{\circ} 1$

La frontera sur de México

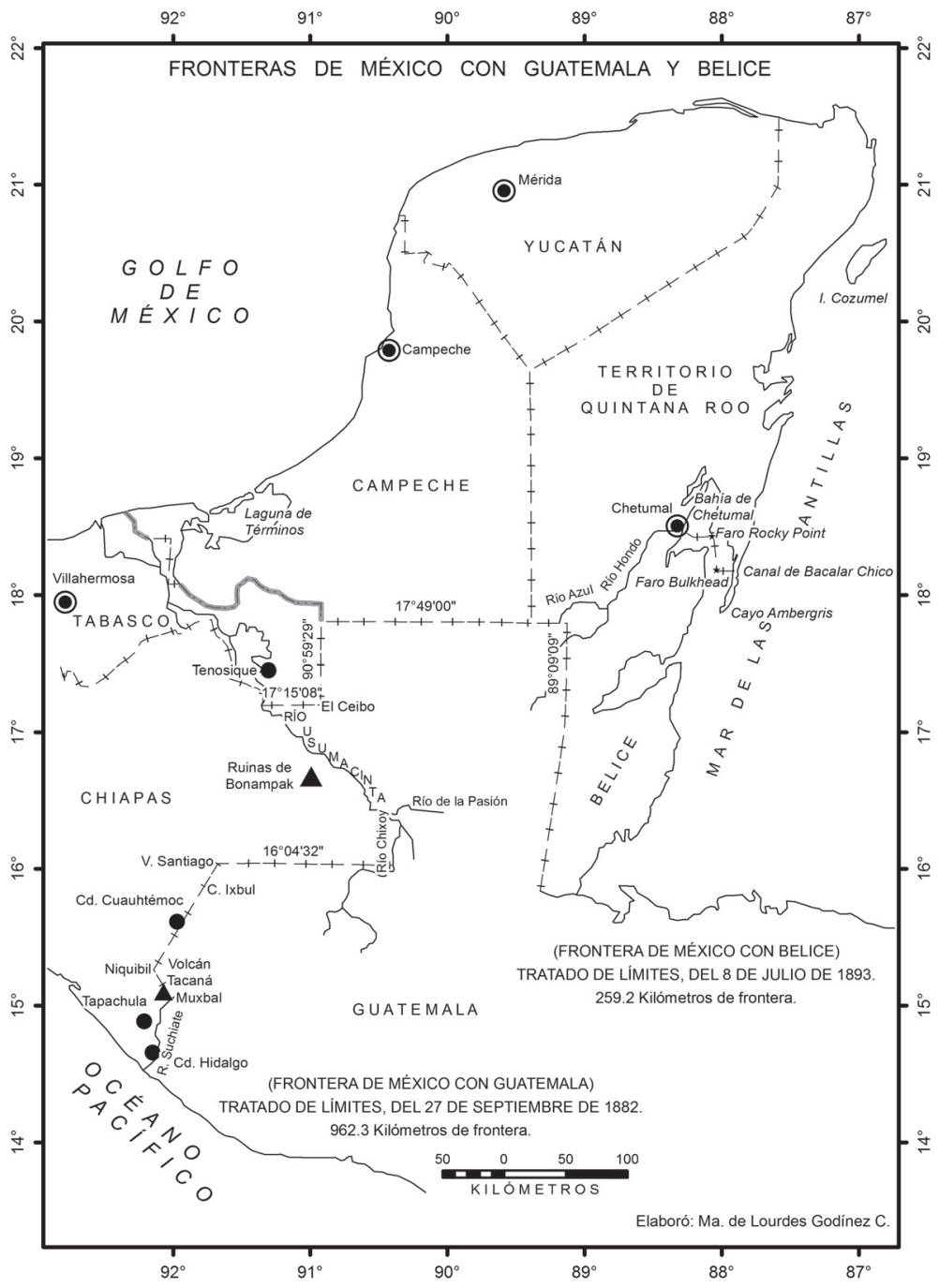

Fuente: Tamayo, 2014: 151, modificado en base a fuentes documentales de la Mapoteca Manuel Orozco y Berra SAGARPA y de la Secretaría de Relaciones Exteriores de México.

iban obteniendo mayores áreas de control, pero no llegaron a establecerse límites territoriales (Muratori, 2007: 125-132).

Después de lograr la independencia de España, las antiguas colonias se fueron consolidando como países, pero la definición de sus fronteras y sus respectivas demarcaciones no se precisaron por diferentes motivos, que van desde discrepancias con los países veci- nos, hasta indeterminaciones causadas por las características propias de sus fronteras ${ }^{9}$.

9 Un ejemplo podría ser la frontera entre Chile y Argentina que, si bien está definida por la frontera natural de los Andes, el establecimiento de una línea en esta región que separe a esos países debe tener un alto grado de dificultad. 
México definió sus fronteras en el siglo XIX y a principios del XX. El territorio mexicano colinda al sur con dos países, de manera que hay dos convenios para su frontera sur; el Tratado de Límites con Guatemala fue firmado en 1882 y el de Belice (entonces Honduras Británica) se firmó en 1893. La frontera sur de México (Figura $N^{\circ} 1$ ) tiene $1.240 \mathrm{~km}$ de extensión. Es importante considerar que, además de la firma de los convenios, su posicionamiento sobre el terreno requería de la intervención de una Comisión Científica que, interpretando el tratado, ubicara en el terreno los puntos que la definen, de acuerdo con la cartografía utilizada en el documento correspondiente. Lo inexacto de dicho material cartográfico y el conflicto existente con Guatemala por la anexión de Chiapas a México, hizo necesario el nombramiento de una comisión integrada por los dos países, que explorara y analizara el terreno con el fin de elaborar una propuesta para el tratado definitivo; en ella se consideraron principalmente límites naturales como ríos, montañas y otros, además de límites artificiales definidos por puntos y líneas obtenidas por métodos astronómicos y topográficos. Sin embargo, cabe preguntarse ¿cómo se logró determinar la frontera sur de México? ¿Qué problemas enfrentaron los comisionados? El objetivo de este artículo es analizar el trabajo de la Comisión Mexicana para demarcar la frontera sur y, con ello, aportar conocimiento a la Historia de la Geografía en México.

\section{Frontera México-Guatemala}

Esta línea fronteriza tiene una extensión de 962 km. Actualmente colindan, por México, los estados de Chiapas, Tabasco y Campeche, y por Guatemala los departamentos de San Marcos, Huehuetenango, Quiché, Alta Verapaz y El Petén. Prácticamente durante todo el siglo XIX, el estado de Chiapas fue motivo de disputas entre ambos países; el problema surgió debido a que durante la época colonial la Capitanía de Guatemala estaba dividida en cuatro intendencias, una de las cuales era Chiapas con su capital Ciudad Real. Esta intendencia era importante porque en 1786, el visitador general José de Gálvez, decretó la unión de los siguientes territorios: las dos alcaldías de Chiapas, a saber, Chiapas de los Españoles o Ciudad Real y Chiapas de los Indios, que se fundieron con el gobierno del Soconusco para formar la Intendencia de Chiapas (Vivó, en: Commons, 1993: 197).

A principios del siglo XIX, cuando las colonias españolas comenzaron a independizarse, se desató en la Nueva España una feroz guerra que terminaría en 1821, cuando Agustín de Iturbide, antiguo militar realista, se reunió con Vicente Guerrero, principal general insurgente sobreviviente, y acordaron unirse para proclamar el Plan de Iguala y terminar de esa manera con la guerra de Independencia de México. Al conocerse esta noticia en Chiapas, se reunieron los miembros del Ayuntamiento de Comitán y firmaron el acta de Independencia de Comitán, bajo los principios del mencionado Plan de Iguala; posteriormente también se declaró independiente Ciudad Real y le siguieron los ayuntamientos de Chiapa y de Tuxtla, así como Guatemala y otros países que hoy integran a Centroamérica, con excepción de El Salvador. Ya desde ese momento las autoridades chiapanecas habían resuelto separarse de la Audiencia de Guatemala, como lo constató Manuel Mier y Terán, representante del gobierno de Iturbide, en su visita a Chiapas. Al ser derrocado Agustín de Iturbide, Ios chiapanecos se rehusaron a reconocer al nuevo gobierno mexicano, aunque poco después recuperaron la confianza, y en junio de 1823 tuvo lugar una consulta popular; no todos los pobladores del antiguo reino de Guatemala estaban convencidos de permanecer unidos a México, ya que mientras los habitantes de Chiapas y el Soconusco buscaban su anexión, otros pugnaban por constituirse como estado independiente ${ }^{10}$ formando la "Provincias Unidas de Centroamérica". Ciudad Real, sin embargo, deseaba la unión con México, y la resolución quedó indefinida un tiempo. En 1824 se levantó un plebiscito y se acordó, por votación de sus habitantes, la agregación de Chiapas y el Soconusco a México ${ }^{11}$

\footnotetext{
10 A estos se les conocería como chiapalibres

11 Las disputas continuaron, ya que algunos pobladores no estaban de acuerdo con esta decisión y pugnaban por declarar la completa independencia de Chiapas, pues tampoco querían seguir perteneciendo a Guatemala. El plebiscito ha tenido muchas críticas y se dice que fue un fraude, pero aunque así hubiera sido, lo cierto es que en varias ocasiones posteriores se comprobó la preferencia de los habi-
} 
(Castillo et al., 2006: 47-51). El territorio del Soconusco, que abarcaba los municipios de Tuxtla Chico, Mazatán y Escuintla, estuvo en debate, ya que Guatemala lo reclamaba como parte de su territorio, a pesar de que se le consideraba territorio neutral. Guatemala, con el fin de solucionar el conflicto, solicitó la mediación de Estados Unidos, lo cual no fue aceptado por México.

En 1832 se reanudó la discusión, debido a un Atlas guatemalteco en donde se daba una versión de los límites con México, y el Soconusco se reconocía como territorio neutral, pero ubicándolo en territorio guatemalteco ${ }^{12}$. En 1842 se canceló la iniciativa de formar la Federación Centroamericana y Antonio López de Santa Anna entonces gobernante mexicano consideró que este hecho anulaba el pacto anterior de neutralidad del Soconusco y envió tropas a ocuparlo, declarando su pertenencia a Chiapas que ya estaba unida a México; la protesta de Guatemala no fue suficiente y los ayuntamientos del Soconusco expresaron decididamente su intención de agregarse a México, por lo que el 11 de septiembre de 1842, el Congreso de México decretó que el Soconusco estaba unido a Chiapas (Commons, 1993: 198).

En 1853 se volvió a intentar llegar a un arreglo; Guatemala exigía a México el pago de medio millón de pesos, lo cual se consideró improcedente por el gobierno mexicano ya que, decían, había sido por voluntad propia de los chiapanecos, y no por conquista, como querían entender en Guatemala. El desacuerdo continuó, numerosos comunicados diplomáticos se intercambiaron entre los dos países, hasta que el 3 de julio de 1874, el ministro mexicano José María Lafragua dirigió una nota al ministro guatemalteco Ramón Uriarte, invitándolo a entablar un diálogo

tantes de Chiapas por México (Castillo, Toussaint y Vázquez, 2006: 49-63).

12 El autor de este Atlas era el guatemalteco Miguel Rivera Mestre. El Atlas, compuesto de ocho cartas, fue publicado gracias al patrocinio del gobernador Mariano Gálvez, y su objetivo era difundir una imagen oficial de Guatemala; en él se incluye no solo el Soconusco como parte de Quetzaltenango, sino también la selva lacandona, incluidas las ruinas de Palenque, aparecían en el mismo dentro de Totonicapán-Huehuetenango (Castillo et al., 2006: 67-75). con el fin de tratar de resolver el problema de los límites entre las dos Repúblicas ${ }^{13}$. Ponía a su consideración el nombramiento de una comisión científica que practicara el reconocimiento y levantara los planos que sirvieran de base a las negociaciones (Pastrana, 1914: 6), pero fue hasta 1877 cuando se firmó un convenio preliminar en el cual Ramón Uriarte por Guatemala e Ignacio L. Vallarta ${ }^{14}$ por México acordaron realizar un análisis de la situación de los límites entre ambos países. Se elaboró un proyecto de límites, en él la línea iniciaba en un punto conocido como la Encantada en el Océano Pacífico; esta propuesta fue modificada posteriormente. El presidente de Guatemala Rufino Barrios, con la intención de solucionar el problema de Chiapas, ordenó a su Ministro de Relaciones, Lorenzo Montúfar, firmar un convenio de Límites con México, a lo cual se negó Montúfar argumentando que Chiapas y el Soconusco pertenecían a Guatemala, y a pesar de que Barrios había aprobado desde principios de los ochenta los acuerdos de la Convención de 1877, Guatemala volvió a reclamar la devolución de esos territorios para intentar formar nuevamente la República Centroamericana. Ante la negativa de México, Guatemala solicitó la intervención de los Estados Unidos como árbitro, México rechazó este procedimiento argumentando que se lesionaba su soberanía sobre unos territorios que eran considerados parte de México desde hacía varias décadas.

La negativa de México suscitó una larga serie de reclamaciones y acusaciones de invasiones y atropellos de uno y otro lado de la frontera, Guatemala intentó desprestigiar a México acusándolo de invadir indebidamente terrenos, aunque en realidad habitantes de ese país habían ocupado terrenos chiapanecos. El gobierno mexicano envió soldados a proteger esos territorios y los ministros mexicanos ${ }^{15}$ declararon que México no tenía

\footnotetext{
13 En 1879 el ingeniero guatemalteco Alejandro Prieto elaboró una detallada carta que nombró Croquis de los terrenos fronterizos entre México y Guatemala desde la Encantada hasta el cerro Ixbul para servir al estudio de la línea divisoria entre ambas Repúblicas, Guatemala 16 de julio de 1876.

14 José María Lafragua murió en noviembre de 1875 y fue sustituido por Ignacio L. Vallarta

15 Ignacio Mariscal primero y Matías Romero después.
} 
fines expansionistas, como argumentaba Guatemala, sino únicamente defender al territorio y a los habitantes de Chiapas y Soconusco que habían manifestado libremente su deseo de pertenecer a México. Los diplomáticos mexicanos se apoyaban en la convención de 1877, en la cual, Guatemala reconocía que Chiapas era parte integrante de México. Montúfar fue destituido por el Presidente guatemalteco, quien personalmente inició las negociaciones con Matías Romero acerca de un Tratado de Límites, evitándose con esto, la intervención de Estados Unidos; sin embargo, los guatemaltecos criticaron la decisión de su Presidente Barrios y continuaron su reclamo que se prolongó por mucho tiempo. Con el fin de solucionarlo se acordó nombrar una comisión mixta que, trabajando en la frontera, contribuyera a la definición de un Tratado de Límites. Así, el gobierno mexicano encabezado por Porfirio Díaz nombró la "Comisión Mexicana de Reconocimiento de la frontera entre México y Guatemala", con el fin de realizar las exploraciones correspondientes que condujeran a una propuesta de límites.

\section{La Comisión de Reconocimiento}

El 7 de diciembre de 1877 los representantes de México, Ignacio L. Vallarta, y de Guatemala, Ramón Uriarte, firmaron un convenio para nombrar una Comisión Mixta de Ingenieros, con el fin de practicar en el terreno los reconocimientos científicos para el establecimiento de los límites entre México y Guatemala. Según el artículo 2 de dicho convenio, la comisión estaría compuesta por doce ingenieros, seis de cada país y algunos ayudantes, quienes se reunirían en Tapachula para acordar como se llevarían a cabo los trabajos, El 11 de febrero de 1878 se firmó un protocolo, en su inciso $3^{\circ}$ dice: "El objeto de esta exploración preliminar será el de formarse una idea de los terrenos que la línea atraviesa y de las dificultades que presenten para la ejecución de las operaciones topográficas" (Urrutia, 1964: 131-138).

La Sección Mexicana estaba integrada por los siguientes ingenieros: José Salazar Ilarregui $^{16}$ (Jefe y 1er. Astrónomo), Jacobo Blanco

\footnotetext{
${ }^{16}$ José Salazar Ilarregui había participado y dirigido la
} Comisión de Límites Mexicana en la frontera con Es-
(Ingeniero Geógrafo y $2^{\circ}$ astrónomo), Miguel Ponce de León (Topógrafo de $1^{\text {a }}$. clase), Carlos Revilla, Ignacio Monterde y Manuel Pastrana (Ingenieros), Rafael Montes de Oca (Naturalista), Ernesto Valdés y Melchor Calderón (Ayudantes), Lauro Aguirre (Secretario) y Joaquín Mendizábal Tamborrel (Ayudante calculador y dibujante) (Urrutia, 1964: 138-139).

La Sección Guatemalteca se integraba con los siguientes ingenieros: Juan de Dios Morales (Presidente), Jorge Vélez, Eduardo Rubio Piloña y José Irungaray (Ingenieros), Pompeyo Monetta y Santiago I. Barberena (Astrónomos) Javier Ramírez, Tadeo Taracena José María Saravia y Ramón Aceña (Ayudantes), Manuel R. Ortega (Secretario), posteriormente se agregaron Ireneo Chacón (Astrónomo) y Rodolfo Chacón (Médico) (Urrutia, 1964: 138).

A la Comisión Mexicana se le solicitaba hacer triangulaciones en donde fuera posible, y tomar los datos de la altitud de los puntos referidos al nivel del mar. Algunas de las instrucciones mencionadas por Pastrana (1914: 64-66) fueron:

3. Las posiciones geográficas de ambos extremos de esta primera sección de la línea actual, se determinarán astronómicamente con la mayor exactitud... [los puntos] notables... [podrán] servir de referencia cuando llegue el caso de establecerse y demarcarse en el terreno la línea limítrofe definitiva entre ambas Repúblicas.

$7 \ldots$ se levantarán planos parciales de los terrenos cuya propiedad se disputa entre ciudadanos mexicanos y guatemaltecos y se indicará en ella la posición de la línea actual en el caso de que esta los corte. Los terrenos disputados son, principalmente, los Ilamados del Bejucal, Piedra Parada, Caballo Blanco, de Altaná y Talquián, Cafetal Juárez, Mesa de Muxbal, Pinabete, Tapizalá, Montenegro, Dolores etc.

tados Unidos en 1849-1857, sin embargo, para entonces ya habían transcurrido más de 20 años y su salud y fortaleza física no eran idóneas y fue bajado en camilla de la cumbre del volcán Tacaná, debido a un enfisema pulmonar que lo obligó a renunciar en 1884. 
8. La Comisión Mexicana, de acuerdo con la Guatemalteca, dejará demarcados sobre el terreno, con señales o monumentos provisionales...

10...el objeto importantísimo de los trabajos... consiste, esencialmente, en la adquisición de cuantos datos son necesarios para la elección más acertada de la línea limítrofe y que mejor se preste a la conservación de la paz y de las buenas relaciones entre los dos países...

13. El Jefe de la Comisión se pondrá también en comunicación con los gobiernos de los Estados de Chiapas, Tabasco, Campeche y Yucatán, con el fin de que le proporcionen las noticias, datos y auxilios que la Comisión pueda necesitar.

El presupuesto anual asignado a la Comisión Mexicana de Reconocimiento de la frontera entre México y Guatemala fue de $\$ 87.900,00$ anuales, el 2 de agosto de 1878, la Secretaría de Relaciones Exteriores de México le dio a Salazar Ilarregui las instrucciones correspondientes; en el punto 2 de estas instrucciones se le pedía hacer el reconocimiento entre la Barra de Ocós (en el Pacífico) y el cerro de Ixbul; lo mismo haría la Comisión Guatemalteca, y al terminar esta primera exploración se dividirían, la Mexicana se trasladaría a la Barra de Ocós y la Guatemalteca se trasladaría el cerro de Ixbul, y se les pedía situar algunos puntos específicos como el rancho La Encantada, Caballo Blanco y otros (Pastrana, 1914: 64-66). Cuando comenzaron sus operaciones enfrentaron varias diferencias y problemas, muchas veces provocados por algunos civiles como el contratista Miguel Torruco, quien talaba árboles en esa zona (Castillo et al., 2006: 149).

Así, la Comisión Mexicana de Reconocimiento salió de la Ciudad de México el 30 de septiembre de 1878 y llegó a Tapachula el 17 de noviembre; el 18 se reunieron con los integrantes de la comisión guatemalteca y levantaron el acta correspondiente, en donde se indicaba que iniciarían los trabajos para los que fueron convocados y acordaron que se formaran dos grandes secciones integradas por ingenieros de los dos países. La primera sección iniciaría en la Barra de Ocós, que es en donde desemboca el río Suchiate al Océa- no Pacífico y seguirían hacía el norte por este río. La segunda sección se reuniría en el poblado de Unión Juárez (al norte de Tapachula y cercano al volcán Tacaná); desde este Volcán se dirigirían hacia el sur, para encontrar a la otra sección que vendría midiendo hacia donde ellos se encontraban. Se les pedía que hicieran triangulaciones, marcaran rumbos y distancias, siguiendo y explorando los ríos y cumbres de la región.

Por considerarlo conveniente, los jefes de las Comisiones (Salazar y Morales) irían en la sección del Tacaná. Debido a los numerosos ríos de la región, la sección de la Barra de Ocós se subdividió de manera que la sección mexicana levantaría los planos del río Suchiate desde su desembocadura hasta su confluencia con el río Cabús, y la guatemalteca levantaría el plano del Suchiate desde su confluencia con el Cabús hasta encontrar el río Petacalapa. Las secciones debían elaborar el plano del río Suchiate y el de los afluentes que se encontraran en los tramos referidos, la triangulación hecha por los ingenieros mexicanos para trazar la línea entre el río Suchiate y la garita de Talquián, que corresponde a la primera línea geodésica que cruza por el Volcán del Tacaná17.

Durante estos trabajos se presentaron muchas dificultades, se habían acordado dos años para realizar este reconocimiento, sin embargo, concluido el plazo no se tenía todavía el análisis completo ${ }^{18}$ (Pastrana, 1914: 69-72; Urrutia, 1964: 138-141). El Ing. Mora-

\footnotetext{
17 El mapa fue elaborado por Melchor Calderón de la Comisión Mexicana de Límites, está resguardado en la Mapoteca Manuel Orozco y Berra de la SAGARPA, con la referencia: CLMG 02-8084.

18 Según Pastrana, Guatemala señalaba que los trabajos se habían prolongado mucho y el gasto había sido excesivo, relata que los gastos de Guatemala habían sido mayores debido a que Guatemala le pagaba más a su comisión que México a la suya (Pastrana, 1914: 74). Urrutia en cambio señala que el convenio del 7 de diciembre de 1877 había sido perjudicial para Guatemala; en ese convenio se nombraba a la Comisión de Reconocimiento integrada por los dos países y su inconformidad se debía a que no aceptarían los puntos propuestos por la Comisión mixta, sino los que tenían Chiapas y Soconusco con la Nueva España. Al quedar disuelta la parte guatemalteca de la Comisión de Reconocimiento (en mayo de 1879), su representante, Lorenzo Montúfar, insistió en el arbitraje de un país
} 
les, Jefe de la Comisión Guatemalteca, había acordado con Salazar la metodología que seguirían, pero presionado por su gobierno propuso hacer solamente:

“una simple inspección del terreno,... no esforzarse en obtener la exactitud matemática que solo se debe emplear en circunstancias muy excepcionales como sería el trazo de un meridiano... bastaría que una comisión compuesta de dos o tres individuos competentes de cada República, asociados reconociesen e inspeccionasen la línea divisoria antigua del Departamento del Soconusco... para lo cual deberán tener a su disposición los Archivos de las municipalidades de los pueblos fronterizos" (Pastrana, 1914: 74).

Francisco Díaz Covarrubias, entonces Ministro Plenipotenciario en Guatemala, en una comunicación con el gobierno mexicano apoyó la opinión de Morales, pero Pastrana señaló que esto se debía al desconocimiento que tenía Díaz Covarrubias del clima y terreno en donde se estaba trabajando. A pesar de que Guatemala disolvió su comisión, México ordenó que los mexicanos continuaran sus trabajos hasta terminarlos, sin fijar fecha precisa. Cuando se tuvieron los datos, se solicitó una reunión a Manuel Herrera, Enviado Extraordinario y Ministro Plenipotenciario de Guatemala en México, y se le pidió que en ella estuviera alguno de los ingenieros guatemaltecos que habían integrado la Comisión Mixta de Reconocimiento. Se hizo una propuesta, pero Lorenzo Montúfar, Ministro de Relaciones guatemalteco insistía en el arbitraje de Estados Unidos. México se oponía a ello ${ }^{19}$ por considerar que se le estaba restando validez a la exploración en campo realizada. Varias propuestas y contrapropuestas hicieron José Salazar Ilarregui, José María Lafragua, Francisco Díaz Covarrubias, Antonio García Cubas y Leandro Fernández,

extranjero, lo cual rechazó México (Urrutia, 1964: 141).

${ }^{19}$ El Sr. Salazar Ilarregui, Jefe de la Comisión Mexicana de Reconocimiento de la frontera entre México y Guatemala, se dirigió el 15 de noviembre de 1881 a la Secretaría de Relaciones y manifestó que México nunca debería consentir que la cuestión de límites se resolviera por arbitraje estadounidense (Pastrana, 1914: 119). de México, así como José Irungaray, Ramón Uriarte, Manuel Herrera y Rufino Barrios, de Guatemala; también se estudiaron otras líneas establecidas anteriormente. Con esas opiniones Antonio García Cubas y Leandro Fernández formaron en enero de 1882 una carta que les permitió reunir a los representantes de los dos países para llegar a un acuerdo de límites. Finalmente, en septiembre de ese mismo año, basados en el trabajo de reconocimiento de ambos gobiernos, los ministros Manuel Herrera, de Guatemala, e Ignacio Mariscal, de México, aprobaron el tratado definitivo (Pastrana, 1914: 74-155). En la Figura $N^{\circ} 2$ se presenta el mapa elaborado por la Comisión de Límites a partir del trabajo de Manuel Pastrana durante la Comisión de Reconocimiento, en este mapa se puede ver un tramo del río Tilapa, que junto con los ríos Naranjo y Suchiate, desemboca en la Barra de Ocós en el océano Pacífico, para el tratado definitivo se seleccionó al Suchiate como límite entre México y Guatemala.

\section{El Tratado de Límites entre México y Guatemala}

El Tratado de Límites ${ }^{20}$ entre México y Guatemala fue firmado el 27 de septiembre de 1882; en su artículo primero manifiesta que Guatemala renuncia a sus derechos sobre Chiapas y el Soconusco y en el tercero especifica que el límite entre los dos países debía ser marcado en el terreno por una comisión científica. Dicho artículo indica:

"La República de Guatemala renuncia para siempre a los derechos que juzga tener al territorio del Estado de Chiapas y su Distrito de Soconusco y, en consecuencia, considera a dicho territorio como parte integrante de los Estados Unidos Mexicanos" (Tratados ratificados y convenios ejecutivos celebrados por México, en: De Vos, 1993: 156)

${ }^{20}$ Manuel González, presidente de México y Rufino Barrios de Guatemala habían nombrado a Ignacio Mariscal, Secretario del Despacho de Relaciones Exteriores de México y a Manuel Herrera hijo, Enviado Extraordinario y Ministro Plenipotenciario guatemalteco, para acordar el Tratado de Límites entre las dos Repúblicas, que finalmente fue firmado en 1882 (Pastrana, 1914: 155). 
Figura $\mathrm{N}^{\circ} 2$

Plano del río Tilapa

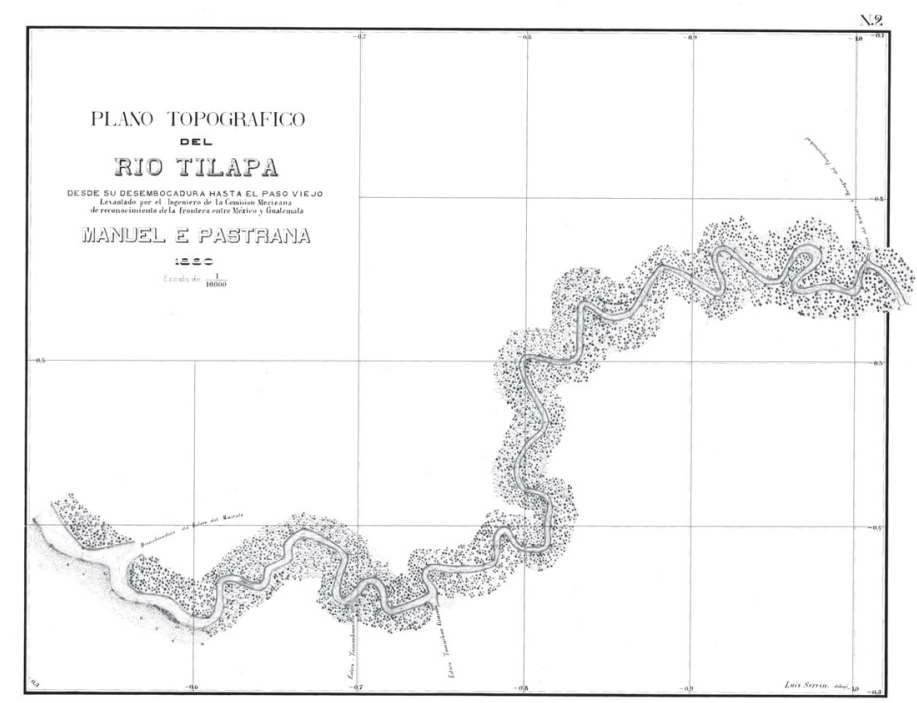

Fuente: Pastrana y Servín, 1880. Mapoteca Manuel Orozco y Berra (MMOB), SAGARPA.

En el artículo segundo se especifica:

"La República Mexicana aprecia debidamente la conducta de Guatemala y reconoce que son tan dignos como honrosos los fines que han inspirado la anterior renuncia, declarando que, en igualdad de circunstancias, México hubiera pactado igual desistimiento. Guatemala por su parte, satisfecha con este reconocimiento y esta declaración solemne, no exigirá indemnización de ningún género con motivo de la estipulación precedente" (Pastrana, 1914: 156).

El artículo tercero señala:

"Los límites entre las dos naciones serán a perpetuidad los siguientes: $1^{\circ}$ La línea media del río Suchiate, desde un punto situado en el mar, a tres leguas de su desembocadura, río arriba por su canal más profundo, hasta el punto en que el mismo río corte el plano vertical que pase por el punto más alto del volcán del Tacaná y diste veinticinco metros del pilar más austral de la garita del Talquián, de manera que esta garita quede en territorio de Gua- temala. $2^{\circ}$ La línea determinada por el plano vertical definido anteriormente, desde su encuentro con el río Suchiate, hasta su intersección con el plano vertical que pase por las cumbres de Buenavista e Ixbul. $3^{\circ}$ La línea determinada por el plano vertical que pase por la cumbre de Buenavista, fijada ya astronómicamente por la Comisión Científica Mexicana, y la cumbre del cerro de Ixbul, desde su intersección con la anterior, hasta un punto a cuatro kilómetros adelante del mismo cerro. $4^{\circ} \mathrm{El}$ paralelo de latitud que pasa por este último punto, desde él, rumbo al Oriente, hasta encontrar el canal más profundo del río Usumacinta, o el del Chixoy, en el caso de que el expresado paralelo no encuentre al primero de estos ríos. $5^{\circ}$ La línea media del canal más profundo, del Usumacinta en su caso, o del Chixoy y luego el Usumacinta, continuando por este, en el otro, desde el encuentro de uno u otro río con el paralelo anterior, hasta que el canal más profundo del Usumacinta encuentre el paralelo situado a veinticinco kilómetros al Sur de Tenosique en Tabasco, medidos desde el centro de la plaza de dicho pueblo. $6^{\circ} \mathrm{El}$ paralelo de latitud que acaba de referirse, 
desde su intersección con el canal más profundo del Usumacinta hasta encontrar la meridiana que pasa a la tercera parte de la distancia que hay entre los centros de las plazas de Tenosique y Sacluc, contada dicha tercera parte desde Tenosique. $7^{\circ}$ Esta meridiana, desde su intersección con el paralelo anterior hasta la latitud de diez y siete grados, cuarenta y nueve minutos $\left(17^{\circ} 49^{\prime}\right) .8^{\circ}$ El paralelo de diez y siete grados, cuarenta y nueve minutos $\left(17^{\circ}\right.$ $49^{\prime}$ ) desde su intersección con la meridiana anterior, indefinidamente hacia el Este" (Pastrana, 1914: 156).

En el artículo cuarto del mismo Tratado se apuntaba el procedimiento que deberían seguir las Comisiones, y se solicitaba llevar diarios de sus operaciones en el campo ${ }^{21}$.

\section{La Comisión de Límites}

Para cumplir con el artículo anterior del Tratado era necesario nombrar las respectivas Comisiones de Límites, así, el 1 de octubre de 1883, la Comisión Mexicana de Límites quedó integrada de la siguiente manera: José Salazar Ilarregui (Astrónomo y Jefe de la Comisión); Próspero Goyzueta y Melchor Calderón (Topógrafos de primera clase); Reinaldo Gordillo y José H. Martínez (Topógrafos de segunda clase); Luis Servín (Ayudante de primera clase); Cristóbal J. Guillén (Ayudante segunda clase); Rafael Montes de Oca (Preparador naturalista) y Fernando Flores (Pagador). Posteriormente se dieron algunos cambios en la Comisión Mexicana y a la renuncia del Ing. Salazar Ilarregui, el 1 de julio de 1884,

\footnotetext{
21 Para trazar la línea divisoria con la precisión debida en mapas fehacientes, y establecer sobre el terreno monumentos que pongan a la vista los límites de ambas Repúblicas según quedan descritos en el anterior artículo, nombrará cada uno de los dos gobiernos una comisión científica. Ambas comisiones se reunirán en Unión Juárez, a más tardar a los seis meses contados desde el cambio de ratificaciones de este Tratado, y procederán desde luego a practicar las expresadas operaciones. Llevarán diarios y levantarán planos de las mismas, y el resultado de sus trabajos, convenido por ellas, se considerará parte del Tratado y tendrá la misma fuerza que si estuviere en él inserto... El plazo para la conclusión de dichas operaciones será de dos años, contados desde la fecha en que las comisiones se reúnan (Pastrana, 1914: 157).
}

ocupó la jefatura de la misma Manuel E. Pastrana, quien se había incorporado a esta, como $2^{\circ}$ astrónomo, desde octubre de 1883 (Pastrana, 1914: 168). La Comisión Guatemalteca de Límites, nombrada el 6 de octubre de 1883 se integraba por: Miles Rock Jefe y Astrónomo de la Comisión; Edwin Rockstroh, Felipe Rodríguez, Manuel Barrera y Claudio Urrutia (topógrafos) y Manuel Amézquita, Fabián Ortíz, Gregorio Contreras y Gaudencio Mora (ayudantes) (Urrutia, 1964: 234-235). Para realizar los trabajos se estipuló un Protocolo (Pastrana, 1914: 166-167), que señalaba:

"Artículo III. Los trabajos puramente astronómicos que deben hacerse cerca de los vértices de las líneas divisorias, se harán separadamente por los astrónomos de ambos países...

Artículo IV. El trazo de las líneas geodésicas convenidas en el Tratado se hará conjuntamente por los astrónomos de ambos países, pero se hará por separado si ellos así lo acuerdan

Artículo V. Para los trabajos puramente topográficos, toda la zona se dividirá en secciones, encomendándose alternativamente a los topógrafos mexicanos y guatemaltecos.

Artículo VI. Se señalarán con monumentos las líneas geodésicas y paralelos de latitud que marca el Tratado, hasta el paralelo $17^{\circ} 49^{\prime}$ indefinidamente al Este. Estos monumentos serán, en general, de mampostería de piedra,... Tendrán la forma de pirámide truncada rematada por otra pequeña pirámide, con una base de un metro por lado y una altura de tres metros sobre el nivel del suelo

Artículo X. A la conclusión de los trabajos se dibujará el plano por duplicado en la escala 1:100 000; lo firmarán, en prueba de conformidad, los jefes de las comisiones, y así firmado, lo entregarán cada uno a su respectivo gobierno, acompañado de sus memorias, los libros originales de campo de su comisión y copias certificadas de los de la Comisión del otro gobierno".

El protocolo definido por José Fernández subsecretario del Despacho de Relaciones 
Exteriores de México y por Manuel Herrera hijo, Ministro Plenipotenciario guatemalteco, se firmó por los mismos el 14 de septiembre de 1883 (Pastrana, 1914: 165). Asimismo, Salazar Ilarregui, estipuló que solo se aceptarían errores mínimos 22 . Recomendó que se aprovechara los planos y exploraciones hechas por Comisión de Reconocimiento y respecto al Usumacinta señaló:

“...estos puntos deberían ser determinados por observaciones astronómicas durante máximo tres noches seguidas para no demorar mucho los trabajos. La longitud se determinará por alturas de la Luna y las estrellas, se dará preferencia a métodos astronómicos sobre los geodésicos y topográficos, por ser más expeditos. El trazo del paralelo $17^{\circ} 49^{\prime}$ no se llevará sino hasta el camino del Petén o un poco más adelante, sin llegar a los terrenos ocupados por Belice (Reino Unido). Formarán croquis de los terrenos recorridos y se tomarán datos que contribuyan al adelanto de la geografía del país" (Pastrana, 1914: 168-170).

La Comisión Mexicana de Límites inició sus trabajos el 1 de diciembre de 1883, José Salazar llarregui insistió en que se nombrara a Manuel Pastrana como $2^{\circ}$ astrónomo de la Comisión, pues su salud no era buena; Salazar dividió la comisión mexicana en cinco equipos, el primero, encabezado por Salazar, hizo el trazo desde el río Suchiate hasta el cerro Ixbul, ahí determinaron un punto Ilamado vértice Santiago, de donde parte el primer paralelo que trazaron Goyzueta y Martínez mediante una triangulación, está definido por la latitud $16^{\circ} 04^{\prime} 32^{\prime \prime}$. Un quinto grupo, encabezado por Gordillo, iría a finalizar el levantamiento de los ríos situados entre Tapizalá e Ixbul y, finalmente, Calderón terminaría de levantar el cauce del río Coatán y del Usumacinta. Salazar determinó que Pastrana y Servín fueran a Tenosique para fijar astronómicamente algunos puntos importantes ${ }^{23}$.

22 En la determinación de latitudes y azimutes se limitará "...a un error probable de más menos 0 ". 5, y la diferencia de meridianos entre Tenosique y Sacluc ,... el error probable aceptable será más y menos 0.1" (Pastrana, 1914: 169).

23 [se les ordenó] "... fijar la posición astronómica de esta población [Tenosique], situar sobre el río Usumacinta el punto en el que éste corta el paralelo
El 2 y 3 de noviembre de 1883 se reunieron en el pueblo de Unión Juárez los comisionados Salazar y Miles Rock y convinieron la manera de trabajar ${ }^{24}$. En junio de 1884 Salazar se separó de la Comisión quedando al frente de la misma Manuel Pastrana (Urrutia, 1964: 139). El primer paralelo $16^{\circ} 04^{\prime} 32^{\prime \prime} .21$ se midió desde el llamado vértice Santiago hasta encontrar al río Chixoy o Salinas, siguiendo este río hacia el norte se une al río Usumacinta; este tramo fue muy conflictivo, ya que el comisionado guatemalteco Miles Rock se negó durante mucho tiempo a firmar la documentación correspondiente y a aceptar los sitios en donde la comisión mexicana había colocado las señales para los monumentos; esto causó problemas y retrasó la terminación de los trabajos, como se puede constatar en la abundante documentación contenida en el diario del comisionado mexicano (Pastrana, 1914: 801-883). Los comisionados enfrentaron varios problemas, por un lado, el clima, ya que llueve prácticamente durante todo el año, la "época de secas" es muy corta, además se registran altas temperaturas en las zonas bajas, la topografía es muy escarpada y difícil, la zona montañosa tiene bajas temperaturas debidas a la altitud, todo esto les dificultaba el trabajo; la espesa vegetación característica de la selva lacandona, permanentemente se encuentra plagada de insectos y animales propios de la región, los cuales fueron un peligro constante para los comisionados; y por si esto fuera poco, tenían que mediar entre los conflictos de los habitantes de la frontera que se acusaban unos a otros de invadir territorios que no les correspondían, entre estos estaban numerosas compañías que talaban árboles de maderas preciosas como la caoba y el cedro; los trabajadores y contratistas de estas compañías tiraban las marcas

situado a 25 kilómetros al sur del centro de la plaza, como estaba especificado en el Tratado, trazar el paralelo y determinar la posición del meridiano, hacer la triangulación entre Tenosique y Sacluc y hacer el trazado de ese meridiano hasta encontrar el paralelo $17^{\circ} 49^{\prime \prime \prime}$ (Pastrana, 1914-169).

${ }^{24}$ Convinieron en informar la falta de material para construir el monumento en la desembocadura del río Suchiate, por lo que recomendaban hacer uno de Hierro o Bronce; también acordaron trabajar separadamente las líneas geodésicas y colocar los monumentos correspondientes después del trazo (Pastrana, 1914: 171-172). 
Figura $\mathrm{N}^{\circ} 3$

Límites entre México y Guatemala

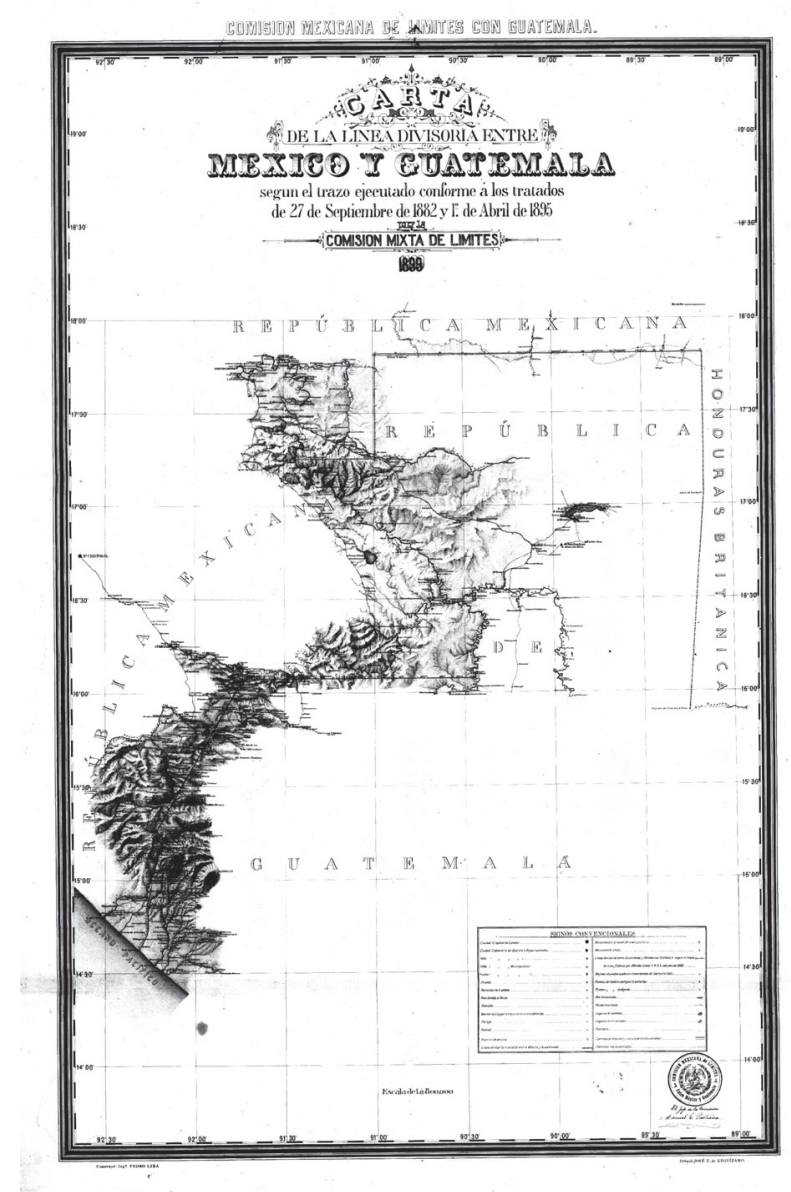

Fuente: Comisión Mixta de Límites, 1899.

puestas por los ingenieros y los agredían. Además, las demandas de Guatemala continuaron, apoyadas en parte por la intervención del ingeniero norteamericano Miles Rock quien había sido contratado por Guatemala para dirigir su Comisión de Límites; Rock elaboró un mapa en donde señalaba, desde su punto de vista, los terrenos que habían sido ilegalmente invadidos por México, así como las irregularidades que supuestamente México había cometido para su beneficio, en la definición de la frontera; sin embargo, del análisis se deduce que todas estas reclamaciones se debían a la existencia de intereses económicos causados por la explotación de los bosques de maderas preciosas (caoba y cedro) localizados en las regiones cercanas a los ríos Lacantún, Chixoy y la Pasión, principalmente.
Otra problemática fue la explotación de las zonas chicleras, de donde obtenían importantes ganancias a costa de la salud de los trabajadores, estas empresas eran difíciles de detener debido a que, por la misma indefinición de los límites, a los inspectores les aseguraban que el terreno que explotaban pertenecía a México o Guatemala según les conviniera. También esa indefinición favorecía el contrabando de licores y de tabaco. El conflicto entre Miles Rock y Pastrana perduró mucho tiempo; Pastrana, por medio de cartas y telegramas, solicitaba continuamente una reunión con Rock para aclarar algunos puntos como los monumentos que el comisionado guatemalteco había mandado colocar apoyándose en su muy particular interpretación del Tratado, pero Rock, mediante pretextos, 
evitaba la reunión con Pastrana y fomentaba el resentimiento del gobierno guatemalteco contra la Comisión Mexicana, ya que argumentaba que los mexicanos colocaban las señales de manera indebida para apoderarse de territorio guatemalteco. El problema fue tan difícil que, para evitarse un enfrentamiento, fue necesaria la intervención diplomática de los dos países; Rock fue destituido de la jefatura de la Comisión Guatemalteca y en su lugar fue nombrado Claudio Urrutia, quien finalmente se reunió con Pastrana en 1896 (Castillo et al., 2006: 153). Aun así, los problemas y reclamaciones continuaron, recrudeciendo el malestar de Guatemala cuando se acordaron los límites con Belice. $\mathrm{Al}$ establecerse definitivamente el límite entre México y Guatemala, tanto uno, como otro país cedieron parte de territorio, México cedía Ayutla y las regiones anexas a Guatemala a cambio de Motozintla y regiones colindantes. Los trabajos se terminaron el 5 de noviembre de 1899, el presidente Porfirio Díaz estableció una oficina en Puebla, en donde se reunieron las dos comisiones con el objeto de dibujar un Atlas y una carta Mural de la Frontera entre México y Guatemala esc. 1:100 000, que fueron entregados al Ministerio de Fomento en 1902, junto con fotografías e instrumentos. En la Figura $N^{\circ} 3$ se reproduce una copia de la carta elaborada por la Comisión de Límites en 1899.

\section{La Frontera entre México y Belice}

Esta frontera tiene una longitud aproximada de $278 \mathrm{~km}$, incluyendo los que corresponden al límite marítimo de la Bahía de Chetumal. Los estados mexicanos de Campeche y Quintana Roo colindan con los distritos beliceños de Orange Walk y Corozal. Después del descubrimiento de América, los españoles habían explorado la costa de Belice, pero hasta mediados del siglo XVI no existían establecimientos permanentes, solo algunos grupos misioneros habían tratado de evangelizar a los indígenas (Toussaint, 1993: 19-21).

La atracción que el Nuevo Mundo ejercía en Europa despertó la codicia y el deseo de dominio económico y político de Isabel I, entonces reina de Inglaterra. Para lograr sus fines alentó la piratería no solo con el objetivo de obtener tierras en el Nuevo Mundo, sino también adueñarse de las riquezas que transportaban los barcos españoles desde América hacia España. De tal manera incitó Isabel I esa actividad que durante su gobierno varios piratas se convirtieron en figuras sumamente populares y atractivas en Inglaterra (De Ita, 2001: 13-17), e incluso, en función del poder económico y bélico que le representaban, les otorgaba el título nobiliario de Sir.

En la isla Tortuga ${ }^{25}$ se había instalado un grupo que se autodenominaba "La Cofradía de los Hermanos de la Costa"; estaba formado por piratas de varias nacionalidades principalmente ingleses, franceses y holandeses, cuya principal actividad era atacar a los buques y puertos españoles (De Vos, 1993: 65). Dos de ellos, John Hawkins y Francis Drake llegaron a utilizar el territorio de Belice y las costas de Yucatán y Campeche, para refugiarse y abastecerse de agua y comida (Toussaint, 1993: 22). Poco a poco se fueron instalando, cambiando su actividad de bucaneros a filibusteros, se apoderaron de islas, lagunas y barreras coralíferas de la costa yucateca que, además de proporcionarles escondite, les permitía de vez en cuando unirse a otros piratas y atacar los barcos mercantes y los puertos españoles. Campeche, Bacalar y Santa María de la Victoria, que estaban situados en la costa, sufrieron varios saqueos de parte de estos grupos. Las autoridades españolas, ante la incapacidad de desalojarlos, optaron por amurallar Campeche y mudar las otras dos poblaciones para el interior. En 1655 las tropas inglesas se apoderaron de la isla de Jamaica y los saqueos empeoraron, pues contaban con la protección del gobierno británico. En 1667, se declaró a la piratería una actividad fuera de la ley, y si bien los saqueos a los barcos disminuyeron, el filibusterismo aumentó, los ingleses se apoderaron de ricas zonas madereras en el litoral, principalmente en la Laguna de Términos, la bahía de Chetumal y Bacalar, en la costa oriental de Yucatán y en la desembocadura del río Belice, explotaban y comercializaban con el palo de tinte.

\footnotetext{
25 Es una pequeña isla situada entre la Isla Española y la de Cuba (De Vos, 1993: 67).
} 
En el siglo XVIII, la corona española expulsó a los antiguos piratas de Yucatán, con excepción de Belice, en donde se había instalado un grupo de madereros que, además de explotar este recurso, desplazaron a la población nativa e importaron grandes contingentes de esclavos negros para hacer el trabajo de corte en los montes; estaban tan enraizados en Belice que fue imposible sacarlos. Ante esto, en 1763 España firmó con Inglaterra el Tratado de París, en donde aceptaba la ocupación inglesa; en 1783 les ratificó la concesión y en 1786 les dio una ampliación, permitiéndoles cortar además del palo de tinte, cedro y caoba, y les autorizó a ocupar las casas y los almacenes que necesitaran para ellos y sus familias en un territorio comprendido entre el mar y los ríos Belice, Nuevo y Hondo ${ }^{26}$. En 1786 la corona española les concedió una ampliación al territorio anterior, el situado entre los ríos Belice y Sibún, y aunque les recalcó que estas tierras pertenecían a España, con esta nueva extensión territorial se fortalecieron e introdujeron mil quinientos esclavos más. Inglaterra, aprovechando la debilidad que pocos años después experimentó España, violando el acuerdo que tenía, ejerció soberanía en estas tierras, extendiendo el área de explotación hacia el occidente y sur, en detrimento del territorio de España, y a pesar de que esas tierras solo se les habían concedido en usufructo, los cortadores beliceños, una vez agotados los recursos forestales, avanzaron hasta el río Hondo primero y después hasta el río Grande, Moho y finalmente hasta el Sarstoon, a pesar de la resistencia de los pobladores mayas localizados en esas regiones.

En 1823, el presidente Guadalupe Victoria se reunió con Patrick Mackie, representante inglés y solicitó que esa nación reconociera la Independencia de México; en respuesta el gobierno inglés envió como diplomáticos a James Morier y Henry George Ward, quienes negociaron el primer Tratado de Amistad, Comercio y Navegación entre México e Inglaterra, mismo que fue firmado el 6 de abril de 1825 (Zorrilla, 1984: 757). En 1826 México y Gran Bretaña firmaron un acuerdo; el primero

\footnotetext{
26 Este territorio abarcaba aproximadamente cuatro mil ochocientos kilómetros cuadrados (De Vos, 1993: 72).
}

se comprometió a no interferir con las actividades de los cortadores de las compañías inglesas, mientras Inglaterra intentaba que España admitiera su posesión y soberanía sobre Belice. En 1836, al reconocer finalmente España la independencia de México, no mencionó lo relativo a Belice ${ }^{27}$ debido al compromiso anterior con Gran Bretaña (Toussaint, 2004: 103). Cuando en 1859 Inglaterra y Guatemala firmaron un convenio, se inició la pérdida real de ese territorio, ya que la segunda aceptaba y cedía a Inglaterra "todo el terreno al norte del río Sarstoon y al oriente de una línea recta tirada desde los raudales de Gracias a Dios en aquel río hasta los de Garbutt en el río Belice, y desde allí, al norte, hasta tocar la frontera mexicana" (De Vos, 1993: 76); Inglaterra a cambio, se comprometía a facilitar a Guatemala una salida al mar a través del territorio ocupado por los cortadores, por el medio que deseara, terrestre o fluvial; sin embargo, Inglaterra nunca cumplió con este compromiso.

En México, durante el imperio de Maximiliano, José Salazar Ilarregui, entonces Comisario Imperial de Yucatán (1865) señaló que los ingleses solo tenían permiso de explotar la madera, pero el territorio pertenecía a Yucatán. Los gobiernos posteriores tampoco aceptaron la cesión del terreno que solicitaba Inglaterra, por lo cual los representantes ingleses encontraron en la guerra de castas que se desarrollaba en Yucatán una salida para lograr la obtención del territorio, ya que, en forma clandestina, proveían armas a los indígenas sublevados, haciendo interminable la guerra y debilitando al gobierno de Yucatán para forzarlo a que cediera esos terrenos. Después de la firma del Tratado de Límites entre México y Guatemala (septiembre 27 de 1882), Inglaterra volvió a insistir en un arreglo de límites. El 13 de julio de 1883, Sir Spencer Saint John llegó a la ciudad de México como enviado de la Reina Victoria de Inglaterra a intentar reanudar las relaciones que se habían roto desde la época de la Intervención Francesa (Cosío, 1974: 774)

\footnotetext{
27 México consideraba que ese territorio era parte de la península de Yucatán y, por lo tanto, le pertenecía.
} 
Diplomáticamente las pláticas entre Ignacio Mariscal de México y Sir Spencer Saint John de Inglaterra se desarrollaron de manera adecuada, Saint John había recibido de su gobierno la sugerencia de forzar el arreglo para que la frontera se estableciera mediante límites naturales, con lo que se notaba la intención de Inglaterra a ganar terreno mediante el reconocimiento del río Sarstoon en el sur y el río Hondo por el norte; los problemas políticos de México influyeron en el retardo de las negociaciones, y mientras la guerra de castas en Yucatán no tenía fin, este gobierno sabía que desde Belice se proporcionaban armas a los sublevados yucatecos, por tanto, con el objeto de terminar definitivamente la guerra, la legislatura de Yucatán presentó una propuesta al gobierno federal en septiembre de 1892, ofreciendo reconocer el establecimiento de los cortadores como colonia británica a cambio de que Gran Bretaña se comprometiera a detener el tráfico de armas y a establecer, de común acuerdo, los límites internacionales. La Comisión Mexicana de Límites, que trabajaba en la frontera con Guatemala recibió instrucciones de prolongar el paralelo $17^{\circ} 49^{\prime}$ indefinidamente hacia el este, sin embargo, la insistencia de Saint John y el objetivo de no tener más problemas en esa frontera llevaron a Mariscal a aceptar el siguiente arreglo:

México aceptó ceder territorio hasta el río Hondo y dividir la bahía de Chetumal, a cambio de que los ingleses se comprometieran definitivamente a terminar con el tráfico de armas y a no seguir avanzando sobre el territorio mexicano, como lo habían hecho hasta entonces. Finalmente, el 8 de julio de 1893, México y Gran Bretaña firmaron el Tratado de Límites entre México y Honduras Británica, donde se hacía mención del Límite acordado entre Guatemala y Gran Bretaña, firmado el 30 de abril de 1850 que lo señalaba como sigue:

"Comenzando en la Boca del río Sarstoon en la Bahía de Honduras, y remontando la madre del río hasta los raudales de Gracias a Dios; volviendo después a la derecha y continuando por una línea recta tirada desde los raudales de Gracias a Dios hasta los de Garbutt en el río Belice, y después de los raudales de Garbutt Norte derecho, hasta donde toca con la frontera mexicana".

\section{El Tratado de Límites entre México y Belice}

El Tratado de Límites firmado el 8 de julio de 1893 entre Ignacio Mariscal representante de la República Mexicana y Sir Spenser Saint John representando a su Majestad Británica señalaba lo siguiente:

"Artículo I: Comenzando en Boca de Bacalar Chica, estrecho que separa el Estado de Yucatán del Cayo Ambergris y sus islas anexas, la línea divisoria corre en el centro del canal, entre el referido cayo y el continente, con dirección al sudoeste hasta el Paralelo $18^{\circ} 09^{\prime}$ Norte y luego al Noroeste a igual distancia de dos cayos, como está marcado en el mapa anexo, hasta el paralelo $18^{\circ} 10^{\prime}$ Norte; torciendo entonces hacia el Poniente, continúa por la Bahía vecina, primero en la misma dirección hasta el Meridiano $88^{\circ} 02^{\prime}$ Oeste; entonces sube al norte hasta el paralelo $18^{\circ} 25^{\prime}$ Norte; de nuevo corre hacia el Poniente hasta el meridiano $88^{\circ} 18^{\prime}$ Oeste, siguiendo el mismo Meridiano hasta la latitud $18^{\circ} 28^{\prime} 1 / 2$ Norte, a la que se encuentra la embocadura del río Hondo, al cual sigue por su canal más profundo, pasando al poniente de la isla Albión y remontando al Arroyo Azul hasta donde este cruce el Meridiano del Salto de Garbutt, en un punto al Norte de la intersección de las líneas divisorias de México, Guatemala y Honduras Británica, y desde ese punto corre hacia el Sur hasta la latitud $17^{\circ} 49^{\prime}$ Norte, línea divisoria entre la República Mexicana y Guatemala; dejando al Norte en territorio mexicano el Ilamado Río Snoshá ó Xnohhá" (AHSRE Tratados, 1972, Tomo II: 329-331).

El 29 de julio de 1897 se adicionó un artículo al Tratado de Límites con México que aseguraba la libre navegación por las aguas de Honduras Británica de los buques mercantes mexicanos, el artículo firmado por Ignacio Mariscal Secretario de Relaciones Exteriores, representando al Presidente Porfirio Díaz de México y por Sir Henry Nevill Dering, Baronet de Inglaterra, Caballero de la muy Honorable Orden del Baño, enviado Extraordinario y Ministro Plenipotenciario de su Majestad Británica (AHSRE, 2005-7 f4) puntualiza lo siguiente: 
"Artículo III Bis: Su Majestad Británica garantiza a perpetuidad, a los barcos mercantiles mexicanos, la libertad absoluta, que disfrutan al presente, de navegar por el estrecho que se abre al Sur del Cayo de Ambergris, conocido también por la Isla de San Pedro, entre este Cayo y el Continente, así como la de navegar en las aguas territoriales de Honduras Británica" (AHSRE, 2005-7 f4).

En 1898, Othon P. Blanco fue enviado a fundar Payo Obispo (hoy Chetumal), con el fin de establecer ahí un punto migratorio y aduanal que permitiera controlar el contrabando, así como procurar la pacificación de una zona tanto tiempo dañada por la guerra de castas; sus pobladores iniciales fueron mayas, yucatecos y descendientes de ambos que vivían en el norte de Belice y que migraron hacia esta población. Al crearse Quintana Roo en 1902, se instaló en esta zona una colonia penal a donde eran enviados presos políticos enemigos del régimen porfirista. Se encargó a la Comisión Geográfica de la República de la Dirección de Estudios Geográficos y Climatológicos, la elaboración de la carta correspondiente, la cual fue publicada

Figura $\mathrm{N}^{\circ} 4$

Límite entre México y Belice

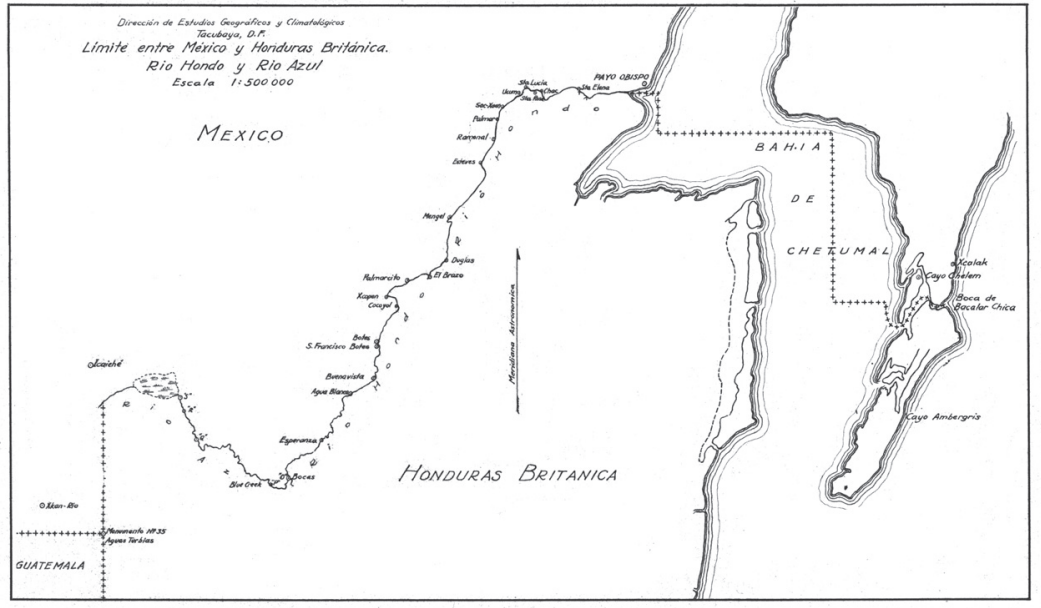

Fuente: Dirección de Estudios Geográficos y Climatológicos, Mapoteca Manuel Orozco y Berra, SAGARPA.

en 1904, en dicha carta se señaló la posición geográfica de Payo Obispo ${ }^{28}$, los cauces de los ríos Azul y Hondo así como el límite marítimo (Figura $\mathrm{N}^{\circ} 4$ ).

\section{La Comisión de Límites}

Como la frontera con Belice estaba definida por los ríos Azul y Hondo y este

\footnotetext{
${ }^{28}$ La situación geográfica de Payo Obispo fue, $18^{\circ} 29^{\prime}$ latitud norte y $88^{\circ} 17^{\prime} 30^{\prime \prime}$ longitud oeste de Greenwich.
}

último era navegable en su desembocadura y en un gran tramo de su cauce, se presentó un problema por la acumulación de material que habían dejado en el mismo las compañías madereras, que impedía el paso libre de embarcaciones y constituía un obstáculo para el reconocimiento y la exploración del río que debía hacer la Comisión de Límites, por tanto, el 5 de enero de 1903, Ignacio Mariscal dirigió una carta a George Greville, enviado extraordinario y Ministro Plenipotenciario de Gran Bretaña, señalando que México contribuiría con los 
gastos de los trabajos de limpieza ${ }^{29}$ (AHSRE, exp. 5002-7, f. 74). Posteriormente en una carta fechada en Belice el 20 de enero de 1905, León Gómez, integrante de la Mesa de Límites de México en Belice, se dirigió al Secretario de Relaciones Exteriores informándole que estaban por emprenderse los trabajos de dragado en el río Hondo, a partir de un informe del Ing. Alex M. Lane (contratado por el gobierno de Belice); León Gómez pedía la intervención del gobierno mexicano porque consideraba que si se llevaban a cabo los trabajos como lo había sugerido Lane, el resultado sería: "la obstrucción de la barra de dicho río en el lado mexicano" (AHSRE, exp. 5002-14, f. 80) y anexaba el informe mencionado, el cual se había publicado en la Gaceta el día 14 de enero de 1905. En respuesta Porfirio Díaz solicitó a la Secretaría de Comunicaciones su intervención, para lo cual fue nombrado el ingeniero mexicano Gabriel Rivera Quiroga, quien mediante un oficio, el 13 de mayo de 1905, envió un estudio con su propuesta para el desazolve del río Hondo en su barra y desembocadura; su estudio lo acompañó de planos, y Antonio García Cubas dio noticia de esto el 14 de abril de 1906 (AHSRE, exp 5002-14, f. 155-156). Posteriormente se nombró a los ingenieros Cristóbal González y Juan G. Morales, con el fin de que revisaran el trabajo que estaba haciendo el gobierno de Belice y analizaran si estos perjudicaban a México; así, en un oficio recibido por Cosío de la Secretaría de Relaciones Exteriores, dichos ingenieros informaron que se habían dragado sobre el río 50 metros de largo por 5 de ancho en dirección de la desembocadura, pero tenían que abrir el ancho del río hasta 15 o 20 metros. Estos ingenieros señalaban que el problema era que no se habían tomado las medidas necesarias para asegurar la permanencia del desazolve, "ya que no tiene protección

\footnotetext{
29 Los trabajos propuestos por los ingenieros mexicanos fueron: "destronconamiento hasta una profundidad de 8 pies bajo el nivel de las aguas de estiaje, limpia de árboles caídos; desmonte de $41400 \mathrm{~m}$. dragado de un canal curvo de $754 \mathrm{~m}$. de longitud por $80 \mathrm{~m}$ de ancho; el volumen por extraer sería de $17578 \mathrm{~m}^{3}$, alcanzando una profundidad de 7 pies de marea media y extracción de la madera que ha quedado con motivo del alijo de las embarcaciones" (AHSRE exp. 5002-14, f. 102-105).
}

contra los vientos reinantes, de manera que éstos, las mareas y las corrientes del río volverán a transportar la misma arena extraída, la cual volverá a azolvarlo" (AHSRE, exp. 5002-14, f. 162-163).

A pesar de que con anterioridad se había convenido en que el desazolve del río lo harían los dos países (México y Honduras Británica), y los costos serían financiados por partes iguales, el gobierno inglés decidió hacer el trabajo solo. Así, el 18 de mayo de 1906, se estimó que, al dividir el cauce para hacer dos canales, México saldría perjudicado, ya que "se modificará el régimen del río, porque las aguas seguirán de preferencia el citado canal y probablemente se azolvará la parte del río correspondiente a México" (AHSRE, exp. 5002-14, f. 170). El 9 de mayo de 1907, Antonio García Cubas $^{30}$ señalaba que la resolución tomada por Honduras Británica de dividir el cauce del río Hondo en dos canales había hecho que se perdiera la ventaja de hacer navegable dicho río, por tanto, envió al gobierno de ese país un comunicado para que quedara una constancia y se evitaran posibles dificultades (AHSRE, exp. 5002-14, f. 202). Finalmente, el 7 de enero de 1909, Ignacio Mariscal anunciaba que el gobierno de Honduras Británica estaba realizando los trabajos para hacer un solo canal, como había recomendado el gobierno mexicano, de acuerdo con los análisis de los ingenieros comisionados (AHSRE, exp. 5002-14, f. 229). La Secretaría de Relaciones Exteriores encargó a la Dirección de Geografía y Meteorología (1946-1953) la triangulación de los límites de México con Belice. En 1925, Pedro C. Sánchez, Jefe de La Dirección de Estudios Geográficos y Climatológicos, principal órgano cartográfico de México en ese tiempo, realizó la cartografía de los ríos Azul y Hondo, fronteras naturales entre los dos países, en este mapa se pueden ver los faros que señalan el límite marítimo (Figura $N^{\circ} 5$ ), y así quedó concluido el establecimiento de este límite.

\footnotetext{
30 Antonio García Cubas, se desempeñaba como de Jefe de la Mesa Especial de Límites y Consultoría de la Secretaría de Relaciones Exteriores en la Ciudad de México (Pichardo, 2004: 173).
} 
Figura $N^{\circ} 5$. Frontera entre México y Belice

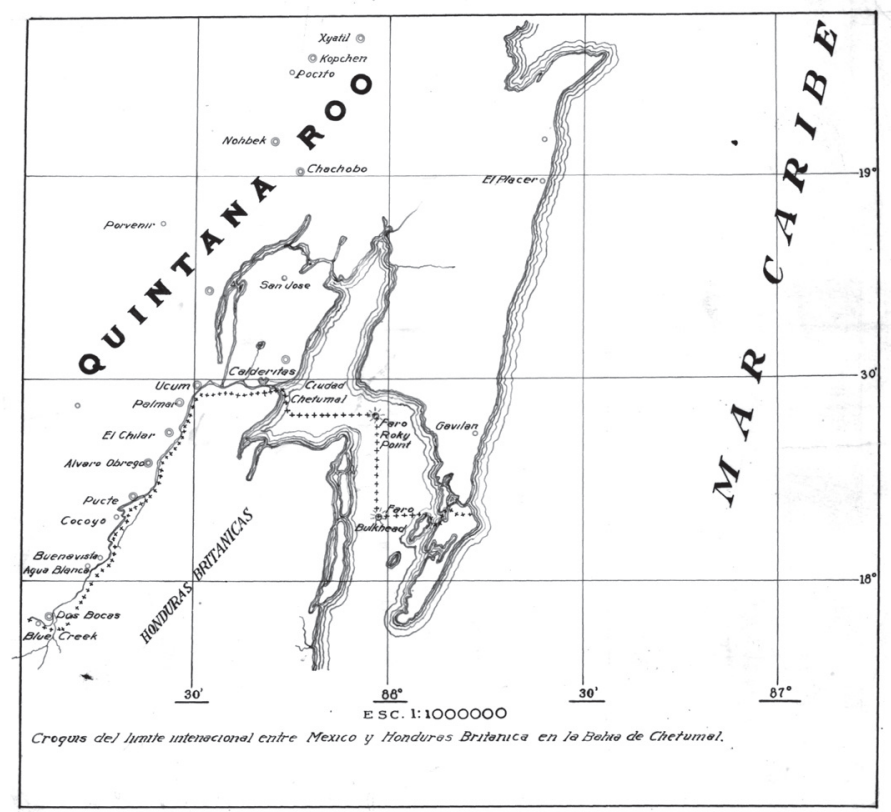

Fuente: Croquis del límite Internacional entre México y Honduras Británica en la bahía de Chetumal, Esc 1:1 000 000, CGLMB01, 10348-ACGE-7216-A, Mapoteca Manuel Orozco y Berra, SAGARPA.

\section{Conclusiones}

La frontera sur, en su mayor parte, es una frontera natural, por lo tanto, es formal, y tiene una parte artificial, definida por una línea trazada en el terreno mediante monumentos. Por el intercambio de personas podría decirse que es una frontera viva, aunque el paso de las personas tiene un componente predominantemente ilegal, debido a la intención de cruzar con el fin de llegar a los Estados Unidos de Norteamérica; así, desde este punto de vista, es una frontera blanda, porque la cruzan muchas personas, pero, a la vez es dura, por las dificultades y agresiones que sufren quienes la cruzan.

La definición de la línea limítrofe sur del país es resultado de diversos trabajos y exploraciones, y ha sido objeto de numerosas controversias. La frontera entre México y Guatemala fue muy difícil de acordar, debido a la disputa por Chiapas y el Soconusco, que ha- bían pertenecido a la Capitanía de Guatemala durante la época colonial; su separación de Guatemala constituyó una gran pérdida para ese vecino país, y su anexión a México fue la causa de muchos enfrentamientos durante gran parte del siglo XIX. En cuanto al límite con Belice, la mayor parte del mismo está definido por los ríos Azul y Hondo, los cuales habían sido explorados por la comisión entre México y Guatemala, ya que ambos países tienen frontera con Belice, país denominado entonces como Honduras Británica. La reina Victoria de Inglaterra y el presidente de México Porfirio Díaz, a través de sus respectivos ministros llegaron a un arreglo; el tratado con México se firmó en 1893.

El trabajo científico hecho por los ingenieros de México y Guatemala consistió, primero, en hacer una exploración en el terreno, con el fin de proponer un límite $y$, una vez firmado el tratado correspondiente (1882), se procedió a fijar los puntos en el terreno. Los 
ingenieros de la Comisión Mexicana de Reconocimiento primero y de Límites con Guatemala después, trabajaron en el campo desde 1878 hasta 1899, y esto requirió de un gran esfuerzo y sacrificio por parte de los comisionados; las coordenadas de cada uno de los puntos que marcan el límite fueron obtenidas por métodos astronómicos y topográficos, lo cual en ese tiempo era un trabajo laborioso que requería de mediciones del Sol, observaciones estelares y triangulaciones topográficas, así que trabajaban de día y de noche; los valores obtenidos les permitían calcular la latitud y longitud de los puntos respectivos; todo esto en medio de un ambiente poco saludable, con vegetación exuberante y fauna nociva propias de esa región, las lluvias constantes y continuas, los ríos caudalosos y la irregular topografía añadieron dificultades para la realización de estos trabajos. Además, la riqueza maderera que contenía había atraído a compañías de taladores que entorpecían a propósito el trabajo de los comisionados. La definición de la frontera con Belice fue terminada por la Comisión Geográfica de la República, dependiente de la Dirección de Estudios Geográficos y Climatológicos, principal organismo cartográfico nacional de ese tiempo, la cual se basó en las exploraciones de los ríos Azul y Hondo hechas por los ingenieros mexicanos en el límite con Guatemala; estos ríos marcan la mayor parte de la frontera entre México y Belice.

Los ingenieros geógrafos que se encargaron de esos trabajos cumplieron su compromiso definiendo la frontera sur y haciendo con ello un gran servicio al Estado mexicano. Además, la metodología desarrollada y la precisión de estos trabajos fueron determinantes para apoyar la cartografía elaborada posteriormente por los diferentes organismos gubernamentales, y esto constituyó un aporte importante al avance de la Geografía en México. Este trabajo intenta añadir un capítulo a la Historia de la Geografía y permite hacer un reconocimiento a la labor de los ingenieros geógrafos mexicanos participantes.

\section{Referencias bibliográficas}

ARCHIVO HISTÓRICO DE LA SECRETARÍA DE RELACIONES EXTERIORES (AHSRE). Tratados ratificados y convenios ejecutivos celebrados por México, Tomo II, 1972.
ARCHIVO HISTÓRICO DE LA SECRETARÍA DE RELACIONES EXTERIORES (AHSRE). Límites República Mexicana-Honduras Británica; Informe del C. Ignacio Mariscal, Secretario del Despacho de Relaciones Exteriores, rendido ante el Senado acerca del Tratado de Límites entre Yucatán y Belice. México: Expediente 5002-7 caja 9, Secretaría de Agricultura y Fomento, Imprenta de F. Díaz de León Sucursal Sociedad Anónima, 1893.

ARCHIVO HISTÓRICO DE LA SECRETARÍA DE RELACIONES EXTERIORES (AHSRE). Límites México-Guatemala Belice. Datos de las triangulaciones hechas con croquis respectivos expediente 5002-14, Secretaría de Agricultura y Fomento.

ARCHIVO DE LA MAPOTECA MANUEL OROZCO Y BERRA (MMOB). Carpetas: Límites México-Guatemala-Belice; Comisión de Límites México-Guatemala, Comisión Mixta de Límites; Dirección General de Estudios Geográficos y Climatológicos.

CASTILLO, M.A.; TOUSSAINT R., M. y VÁZQUEZ O., M. Espacios diversos, historia en común. México: Colección México y sus fronteras, Frontera Sur, Secretaría de Relaciones Exteriores, 2006.

COMISIÓN MIXTA DE LÍMITES. Carta de la Línea Divisoria entre México y Guatemala según el trazo ejecutado conforme a los tratados de 27 de septiembre de 1882 y el 1 de abril de 1895, esc. 1:800,000. Mapoteca Manuel Orozco y Berra (MMOB), SAGARPA.

COMISIÓN DE LÍMITES ENTRE MÉXICO Y GUATEMALA. Límites México-Guatemala. Colección Orozco y Berra, Varilla: CLMG01, No. Clasificador: 10581-CLMG-7216-A, 1899.

COMMONS, A. Las Intendencias de la Nueva España. México: Universidad Nacional Autónoma de México, 1993, p. 197-198.

COSIO, V.D. Historia Moderna de México. El Porfiriato, La Vida Política Exterior de México. Segunda parte. Méxic: Ed. Hermes, 1974, T. VI.

CROQUIS DEL LÍMITE INTERNACIONAL ENTRE MÉXICO Y HONDURAS BRITÁNICA EN LA BAHÍA DE CHETUMAL. Mapoteca 
Manuel Orozco y Berra (MMOB), SAGARPA, esc. 1:1 000 000, Colección General, varilla CGLMB01, No. Clasificador: 10348-A-CGE7216-A s/f.

DE ITA, L. Viajeros Isabelinos en la Nueva España. México: Fondo de Cultura Económica, Universidad Michoacana de San Nicolás de Hidalgo, 2001.

DE VOS, J. Las fronteras de la Frontera Sur, Reseñas de los proyectos de expansión que figuraron la frontera entre México y Centroamérica. Villahermosa: Universidad Juárez Autónoma de Tabasco, 1993.

DIRECCIÓN DE ESTUDIOS GEOGRÁFICOS Y CLIMATOLÓGICOS, Límite entre México y Honduras Británica-Conjunto ríos Hondo y Azul. Mapoteca Manuel Orozco y Berra (MMOB), SAGARPA, esc. 1:500 000 (heliográfica azul) Colección General, varilla CGLMB01, No. Clasificador: 10348-A-CGE7216-A, s/f.

HIGUERAS A. Análisis histórico de las fronteras europeas. En: LÓPEZ TRIGAL, L. (coordinador). Fronteras Europeas y Latinoamericanas. León: Universidad de León, 2007, p. 29-55.

MURATORI, A. Fronteras conceptos y caracterización espacio-temporal. En: LÓPEZ TRIGAL, L. (coordinador). Fronteras Europeas y Latinoamericanas. León: Universidad de León, 2007, p. 13-25.

MURATORI, A. Fronteras y naturaleza en América Latina. En: LÓPEZ TRIGAL, L. (coordinador). Fronteras Europeas y Latinoamericanas. León: Universidad de León, 2007, p. 125-143.

PASTRANA, M.E., Memoria sobre la cuestión de Límites entre México y Guatemala y sobre los trabajos ejecutados en la frontera de ambos países, por la Comisión Mexicana de Reconocimiento de dicha frontera primero y por la Comisión Mexicana de Límites para el trazo de la Línea Divisoria entre ambas República (Cinco partes). México, 1914.
PASTRANA, M.E. y SERVÍN, M.L. Plano topográfico del río Tilapa desde su desembocadura hasta el Paso Viejo, Comisión Mexicana de Límites con Guatemala, Mapoteca Manuel Orozco y Berra, SAGARPA, CLMG02, No. Clasificador 8061-CLMG-7216-A-2, 1880.

PICHARDO, H. Hacia la conformación de una Geografía Nacional: Antonio García Cubas y el territorio mexicano, 1853-1912. México: Tesis para obtener el grado de maestro en Historia, Universidad Nacional Autónoma de México, 2004.

TAMAYO, L.M.O. Las fronteras de México: Apuntes de su demarcación científica técnica en el siglo XIX. Cuadernos de Geografía, Revista Colombiana de Geografía, 2014, Vol. 23, № 2, p. 139-157.

TAYLOR, L.D. El desarrollo histórico del concepto de frontera. En: CEBALLOS, M. (coordinador). De Historia e historiografía de la Frontera Norte, Nuevo Laredo, Tamaulipas, México, Universidad Autónoma de Tamaulipas, Colegio de la Frontera Norte, 1996, pág. 29-55

TOUSSAINT, R.M. Belice, una historia olvidada. México: Instituto de Investigaciones Dr. José María Luis Mora, Centro de Estudios Mexicanos y Centroamericanos, 1993.

TOUSSAINT, R.M. Belice, Textos de su historia, 1670-1981. México: Instituto de Investigaciones Dr. José María Luis Mora, Centro de Estudios Mexicanos y Centroamericanos, 2004.

URRUTIA, C. Memoria sobre la cuestión de Límites entre Guatemala y México, presentada al Señor Ministro de Relaciones Exteriores por el Jefe de la Comisión Guatemalteca, 1900. México: Centro Editorial José de Pineda Ibarra, Guatemala, C.A, 1964.

ZORRILLA, L. Relaciones de México con la República de Centro América y con Guatemala. México: Biblioteca Porrúa, № 82, Ed. Porrúa, 1984. 